\title{
Integrated Product Service Offerings for rail infrastructure: benefits and challenges regarding knowledge transfer and cultural change in a Swedish case
}

Sofia Lingegård and Mattias Lindahl

\author{
Linköping University Post Print
}

\section{Tweet}

N.B.: When citing this work, cite the original article.

Original Publication:

Sofia Lingegård and Mattias Lindahl, Integrated Product Service Offerings for rail infrastructure: benefits and challenges regarding knowledge transfer and cultural change in a Swedish case, 2015, Journal of Cleaner Production, (98), 166-174.

http://dx.doi.org/10.1016/i.jclepro.2014.06.039

Copyright: Elsevier http://www.elsevier.com/

Postprint available at: Linköping University Electronic Press http://urn.kb.se/resolve?urn=urn:nbn:se:liu:diva-109976 


\title{
Integrated Product Service Offerings for Rail Infrastructure - Benefits and Challenges Regarding Knowledge Transfer and Cultural Change in a Swedish Case
}

\author{
Sofia Lingegård ${ }^{1}$, Mattias Lindahl \\ Linköping University, Department of Management and Engineering, Environmental \\ Technology and Management, 58183 Linköping \\ ${ }^{1}$ Corresponding author. sofia.lingegard@liu.se, 004613285663
}

\begin{abstract}
The aim of this paper is to investigate potential benefits and challenges regarding knowledge transfer and cultural change from the provider and buyer perspectives when using IPSOs for Swedish rail infrastructure. Considering material use and the importance of availability of the tracks makes rail infrastructure an interesting candidate for a business model based on a life-cycle approach, which can result in a reduction in cost and environmental impact.
\end{abstract}

The concept of the Integrated Product Service Offering (IPSO) has in several business areas proven to be a means with potential to reduce the environmental impact of products and services, increase cost efficiency and quality, and act as a driver for change. The business model, which is based on a lifecycle approach, focuses on the function instead of the initial price of the product.

Among the main findings are the lack of information and knowledge transfer that act as a barrier for innovation, and that the buyer's conservative business culture makes it difficult to implement new types of contracts. Since IPSO contracts require improved information transfer, they could potentially stimulate innovation as well as processes for evaluation of the contracts. By involving the contractors in the design phase their knowledge could be used in a better way, creating a feedback loop from practice to design.

The empirical part, focusing on the rail infrastructure industry in Sweden, has been collected using individual interviews and a group interview approach.

Key words: Rail infrastructure; Long-term contracts; Supplier-buyer relationships; Knowledge transfer. 


\section{Introduction}

Building and maintaining rail infrastructure requires large quantities of materials, and the environmental impact from the upstream production stages is significant (Svensson and Eklund, 2007). Steel, concrete and crushed rock are the three materials that contribute to the majority of the environmental impact, and these are mainly used for steel rails, concrete ties and ballast material (Svensson and Eklund, 2007). There is an aggregated need for maintenance in the Swedish rail infrastructure system, and previous studies conclude that proactive maintenance is a key factor to create a robust infrastructure system (The Swedish Transport Administration, 2013). At the same time, corrective maintenance is increasing in Sweden (Government Offices of Sweden, 2010). This causes problems with the availability of the tracks, due to errors in the system that need to be taken care of. Furthermore, the government focuses on transferring transports from road to train traffic (Government Offices of Sweden, 2010), while the prognosis expects a strong increase in transport of both people and goods on the rail infrastructure through 2050 (The Swedish Transport Administration, 2013). Considering the 40-60 year use phase of the rail infrastructure and the cost of the maintenance, it would make sense to try to decrease the maintenance cost by e.g. using more durable materials.

The Swedish Transport Administration (STA) is the authority that is the dominant actor and owns $80 \%$ of the rail infrastructure in Sweden. The infrastructure is managed by the law of public procurement. Availability of the tracks is the overall parameter that is used to measure the result of the STA. In this paper, the buyer of the infrastructure is the STA, while the providers are the contractors that realize the construction and maintenance of the infrastructure. The terms "contractor" and "STA" will be used interchangeably with provider and buyer respectively in this paper, depending on if empirical information or general theory are presented and discussed.

Every time maintenance is performed or an error corrected, it affects the availability of the tracks to some degree. The parts of the rail infrastructure system that cause most of the delay hours, $60 \%$, are contact wires, shifters, signal control, tracks and positioning systems (The Swedish Transport Administration, 2012) . Mismanagement of the rail infrastructure in Sweden over the past decades has led to a poorly maintained infrastructure and an inefficient organization (Alexandersson and Hultén, 2008; Thompson et al., 1998; Tullberg, 2000).

Considering the large quantities of material used and the importance of availability of the tracks makes the rail infrastructure system an interesting candidate for a business model based on a life-cycle approach, which can result in a reduction in cost and environmental impact. Thus far, the STA has not had a life-cycle approach to its work. There is a need for the STA to start working with the environmental management of products when designing new products, i.e. before introducing them in the material supply chain, to reduce their environmental impact (Svensson, 2006). Certain contracting forms, such as performance contracting, can increase the drivers for change within industry and thereby increase cost efficiency and quality from a life-cycle perspective (The Swedish Agency for Public Management [Statskontoret], 2009). The fact that the provider has control over the whole lifecycle of the product provides incentives to realize more environmentally and economically sound development when considering the whole life-cycle (Lindahl et al., 2009). This type of contracting is also known as an Integrated Product Service Offering (IPSO), and implies that the provider has the responsibility to deliver a result, and therefore has incentives to optimize the use of energy and material. This implies that the provider needs to be in charge of the design phase, where materials are selected and most of the environmental impacts are set, as described in e.g. Lewis and Gertsakis (2001). 
The IPSO has previously been used in several different types of industries. One example is RollsRoyce, which instead of selling an engine to its customers now provides availability in the form of the number of hours the engine is in use (Baines et al., 2007; Erkoyuncu et al., 2011). Another example is a Dutch road infrastructure project where a type of IPSO was used, and where it was concluded that an integration of the life-cycle steps would be a logical approach for sustainable performance (Lenferink et al., 2013).

In many cases the provider of an IPSO knows more about the product than the buyer, creating an information asymmetry, see e.g. van Amstel et al. (2008). Also, during the use phase the provider can gain more knowledge about the product and use it in the design phase to make improvements (Meier et al., 2010; Sundin and Bras, 2005). Since the design and use phases are not in the same contract for rail infrastructure or executed by the same actor, it is relevant to investigate the information and knowledge transfer and see if it can be improved by a change in business model to IPSOs. In this paper, information is seen as data while knowledge includes skills that have been acquired.

However, to become a service provider, considerable changes have to be made within the organization, capabilities and management of the firm (Oliva and Kallenberg, 2003). Earlier research has pointed out the difficulties associated with a traditional mindset among customers (AlonsoRasgado et al., 2004). The need for investigation of knowledge transfer and cultural change provides the focus for this paper. The aim of this paper is to investigate potential benefits and challenges regarding knowledge transfer and cultural change from the provider and buyer perspectives when using IPSOs for Swedish rail infrastructure.

The composition of this paper is as follows. In Chapter 2, the methodology of the study is presented, followed by Chapter 3, where the life-cycle perspective for product development and the concept of the IPSO are described. Chapter 4 presents an overview of the current procurement situation in Sweden for rail infrastructure, based on the literature study as well as empirical information from the respondents. The results from the interviews regarding IPSOs are presented in Chapter 5, followed by the discussion in Chapter 6. Finally, conclusions and future research are presented in Chapter 7.

\section{Methodology}

This paper has an exploratory nature, since IPSO contracts are not commonly used in rail infrastructure and little has been published in this area. The main empirical data have been collected using individual interviews and a group interview.

The individual interview study was performed to gain knowledge about the provider and buyer perspectives, as well as to get an overview of the industry. The interview guide was based on the results from a previous literature study (Lingegård, 2010; Lingegård, 2011), along with an initial interview with a respondent within the STA familiar in the subject of contracts. Two slightly different interview guides were used, one for the STA and one for the contractors. The analysis of the information was made by a comparison among the respondents from the STA, within the group of contractors as well as between the contractors and the STA.

\subsection{Selection of respondents}

In total, 14 respondents were individually interviewed, and the respondents themselves suggested others as potential respondents during the study. Within the STA, the respondents included representatives on a managerial level of both the construction and maintenance parts of the 
organization, as well as a respondent from the top management group. The respondents from the STA are presented in Table 1. Since the STA is the dominant buyer in Sweden the respondents' views are representative for the buying side. Respondents from Investments represent the investment and construction of the infrastructure, both for new infrastructure projects and larger reinvestment projects. The Maintenance respondents are involved in the long maintenance phase of the infrastructure projects. The respondent from Procurement represents a supporting function for purchasing materials. These divisions are of primary interest for this paper and they are currently not cooperating. When the results from the STA respondents were converging and saturation had been reached, with all respondents highlighting similar areas of interest, the interview study for the buyer perspective was concluded.

\begin{tabular}{|l|l|l|}
\hline STA Divisions & Position & Interview time (min) \\
\hline Procurement & Supply Chain Advisor & 63 \\
\hline Maintenance & Operative Maintenance Control & 50 \\
\hline Maintenance & Procurement Manager & 37 \\
\hline Maintenance & Business Developer & 66 \\
\hline Investments & Operative Procurement & 42 \\
\hline Investments & Operative Control and Coordination & 62 \\
\hline Investments & Top Manager & 66 \\
\hline
\end{tabular}

Table 1: The respondents within the Swedish Transport Administration (STA).

The respondents at the STA provided contact information to most of the contractor respondents; others were contacted directly. Six out of seven of the respondents from the contractors' organizations worked in the marketing or business divisions of the companies. The respondents within the organization of the contractors are presented in Table 2, and represent most of the larger contractors in Sweden, and can therefore be said to be representative of the contractors' view. When the results were converging, the interview study for the contractors' perspective was concluded in a similar manner as for the STA respondents.

\begin{tabular}{|l|l|l|}
\hline Contractors & Position of the respondent & Interview time (min) \\
\hline Contractor A & Regional Business Manager & 60 \\
\hline Contractor B & Marketing Manager & 41 \\
\hline Contractor C & Marketing Manager, & 54 \\
\hline Contractor D & Business Area Manager, Maintenance & 37 \\
\hline Contractor E & Business Area Manager, Maintenance & 52 \\
\hline Contractor F & Design Consultant, Project Manager & 52 \\
\hline Contractor G & Marketing Manager & 63 \\
\hline
\end{tabular}

Table 2: Respondents from the contracting side.

Finally, more in-depth information was needed to validate the information from the individual interviews, as well as to gain more knowledge about the perspectives of the construction and maintenance side within the buyer organization. A five-hour long group interview was conducted with three managerial STA respondents from the interview study: the Business Developer and the Procurement Manager for Maintenance and the top manager from Investments. Apart from having knowledge on the topic, the respondents represented both the maintenance and the investments side, had also shown interest in the topic, and were generous and outspoken with their perspectives. Three people from the research team were present to moderate the discussion and ensure it stayed within the focus areas. 


\section{Integrated Product Service Offerings}

\subsection{A life-cycle perspective for product development}

Previous research within the infrastructure industry states that the earlier in the planning process the provider is involved, the better the opportunities are to adapt the content and the realization of the project to its specific conditions and requirements (Nilsson, 2009). The importance of making decisions early in the product development process, when there is still freedom to make changes, has been stated in earlier research (Lindahl, 2005). The further along in the process the more modifications cost, due to the difficulty in making the changes.

The performance of a technology is often displayed in an S-curve, where the performance is plotted against time or engineering effort (Christensen, 1992). In the beginning of the curve differentiation of design is in focus for the market, followed by a standardization phase where a dominant design is set (Trott, 2012). This is when the focus shifts to efficiency and lowering production costs. The dominant design is not always the best or optimal technology, but could instead be the design that has a faster learning curve; the result is that the more learning that occurs, the less likely the actors will be to investigate other technologies, even if they are better (Ahmed and Shepard, 2010).

Learning, culture and habit can lead to inefficiency due to employees' unwillingness to explore new ways of doing things, since this could cause them to lose their positions of control and power (Ahmed and Shepard, 2010). This raises barriers for new technologies that are not part of the dominant technological design to enter the market (Perkins, 2003), resulting in a type of market lock-in. For the rail infrastructure market and technology, lock-ins are e.g. the width of the tracks, the signal system that needs to be compatible with the trains, and there being only one dominant buyer on the market, as is the case for rail infrastructure in Sweden.

\subsection{Introduction to Integrated Product Service Offerings}

The concept of Product Service Systems, or PSS, is defined as "a system of products, services, supporting networks and infrastructure that is designed to be: competitive, satisfy customer needs and have a lower environmental impact than traditional business models" (Mont, 2002). A development of this concept is the Integrated Product Service Offering (IPSO), which emphasizes the integrated development of the product and the service for the offering (Lindahl et al., 2009). The IPSO is the concept used in this paper.

The IPSO has a life-cycle perspective and includes large parts of the value chain in an integrated offering that instead of selling physical products provides functions, service and performance (Sundin, 2006). With integrated development, it is no longer possible to separate the product and the service in the different phases of the life-cycle (Meier et al., 2010). The IPSO provides the supplier with a possibility to increase the value of the solution for the customer by integrating components in new ways (Brady et al., 2005), and is thereby a driver for the development of technical solutions (Lindahl et al., 2009). There are also incentives for the supplier to realize improved economic and environmental development when considering the whole life-cycle (Lindahl et al., 2009).

However, information and knowledge is needed to do so, and it might not always be easily accessible. Between the provider and the user, information asymmetry is found in many cases (Lingegård et al., 2011; van Amstel et al., 2008). Briefly explained, the provider often holds more information about the product than the user. This could be information concerning toxicity of a product, or perhaps how to 
achieve the best energy performance. The reasons for this asymmetry could be diverse, such as a lack of user education or a deliberate strategy from the provider's side. The information and knowledge asymmetry could be a key factor in making the IPSO a meaningful business model, and the provider has the possibility to provide more efficient maintenance or upgrades during the use phase.

\subsection{Developing Integrated Product Service Offerings}

This section presents literature regarding implementation of IPSOs, and has been divided into benefits and challenges.

\subsubsection{Benefits from IPSOs}

Previous research has shown improvement in the environmental and economic performance from the integration of product and service design (Lindahl and Sakao, 2013). It has also been concluded that the IPSO is environmentally and economically preferable compared to traditional product sales (Lindahl et al., 2013). Infrastructure projects procured using integrated contracting including design, construction and maintenance tend to have lower life-cycle costs and are completed faster (Pakkala, 2002). Additionally, using a product-service mix with more durable materials and other designs may prolong the lifetime of the product and potentially optimize maintenance and operations (White et al., 1999).

In a mature market it can be difficult for providers to differentiate their offerings due to standardized technology, which makes the competition focused on price and subsequently results in low profit margins (Mont, 2004). There are innovation possibilities since the offerings follow the customer's needs, but this requires a focus on the whole system with suppliers and buyers (Lindahl et al., 2009; Tukker, 2004). The knowledge that actors gain through experience provides leverage in the process of incremental innovation (Trott, 2012). A benefit mentioned in the literature for IPSOs is the possibility to gain knowledge during the use of the offering to reconfigure or redesign it (Meier et al., 2010). Knowledge is a key issue when talking about production and innovation, and previous research has shown that external sources of knowledge like suppliers and users can be very important for innovation (Malerba, 2002). Involving suppliers early in the product development process can provide designs more suitable for manufacturing and save later manufacturing costs (Chung and Kim, 2003). Apart from the saved cost, a reduced cycle time, improved quality and greater technological improvement are potential benefits from involving suppliers (Handfield et al., 1999). This is possible since the supplier could have greater experience with the technology, providing a reason to integrate the supplier in the process (Handfield et al., 1999).

\subsubsection{Implementation challenges}

To become a service provider, considerable changes have to be made within the organization, capabilities and management of the firm. In fact, this change is considered one of the major barriers for the business model, as it leads to changes both within the organization as well as changes in the relationship with other actors in the product-service chain (Mont, 2002). One of the great challenges with IPSOs is to manage the supply chain, which plays an important role for the business model (Meier et al., 2010; Mont, 2004). Uncertainties related to the supply chain include capacity, resource availability and capability in the supply chain network (Erkoyuncu et al., 2011). Conflicts of interest between the different actors in the supply chain can also be a challenge for IPSOs (Mont, 2002). Another external barrier for IPSOs could be the lack of demand from public procurement, which otherwise could serve as a driver (Mont, 2002). 
The IPSO implies taking over some of the customer's processes, which is a major risk for the provider (Meier et al., 2010). On the other hand, the IPSO also reduces unpredictability and variability of demand during the contract time, which makes risk reduction a driver for the business model (Mont, 2004; Oliva and Kallenberg, 2003). Long-term contracts increase risks and uncertainty, and the risks are caused by uncertainties that for a long-term performance-based contract arise at the bidding stage (Erkoyuncu et al., 2011; Meier et al., 2010). The uncertainties and risks need to be identified, planned, assessed, handled and monitored, and the provider and buyer should cooperate in doing so (Meier et al., 2010).

The transition to an IPSO business model imposes organizational challenges for both provider and buyer. Buyers might lack life-cycle cost knowledge needed to evaluate the offering and understand the concept due to a traditional business mindset (Mont, 2004). The new conditions require that operational and organizational structures for the provider need to be adapted (Meier et al., 2010). For instance, a cross-functional way of working to design an IPSO is a necessity, meaning that representatives from different areas and departments in the provider organization need to be involved (Brady et al., 2005). Since more information is needed, more trust is required between the buyer and provider to achieve this transparency (Lingegård et al., 2010). The IPSO also implies a longer business relationship that needs to be strong for long-term performance (Meier et al., 2010).

Another challenge is the traditional mindset among buyers (Alonso-Rasgado et al., 2004). Instead of focusing on the product price, the buyers need to focus on the price for the whole life-cycle, and these two cannot be directly compared. The buyer needs to learn about the cost structure of the offerings; otherwise, this lack of knowledge could serve as a barrier (Mont, 2002). There is, therefore, a need for models and tools that can illustrate in a simple way the financial benefits of the offers (Berggren and Björkman, 2002). Additionally, buyer acceptance of the offering as well as trust between the actors is of importance (Mont, 2002).

\section{How rail infrastructure procurement works today in Sweden}

The rail infrastructure market operates within the regulations of public procurement, and the STA is the buying actor. In traditional contracting, the life-cycle of the rail infrastructure is divided into several different contracts, with different actors involved in each phase. There is no continuation between constructing and maintaining since these are separate contracts, and there could also be separate contractors who win the contract.

Construction contracts, or Design-Bid-Build contracts, where the procurer specifies what to build, how to build it and how much material should be used, are the most common contracts within the infrastructure construction industry in Sweden (Nilsson et al., 2006; Nilsson and Pyddoke, 2007). Typically, the scope of the projects and the detailed design specifications are realized by consultants on behalf of the STA, and the contractor is obliged to realize the project within the set time, price and standard level (Pakkala, 2002). The choice of tender is mainly based on the lowest price (Hedström et al., 2005). Construction contracts imply that the procurer carries all the risk, and a maximum ceiling for the price is set which does not create any incentives for contractors to make the processes more efficient; instead, they benefit from reaching the maximum sum (Nilsson et al., 2005). A newer type of contracting for building rail infrastructure is the Design-Build contract, where the contractor is responsible for both the more detailed design phase as well as the construction phase (Nilsson, 2009). This provides an opportunity for the contractor to influence the construction, but has so far not been used to a large extent in Sweden. However, sometimes these contracts end up looking a lot like 
construction contracts due to STA, which interferes in the contractor's work. It is similar for the maintenance contracts based on performance where the function is in construction technicalities, since the stretch, design and appearance are already set.

Since 2005, performance contracts have been used for maintenance in Sweden, meaning that the STA procures a set functionality for the track and the contractor decides appropriate measures to take while still considering maintenance regulations (The Swedish National Audit Office [Riksrevisionen], 2010). Performance contracts are similar to Design-Build contracts in that the contractor is responsible for parts of the detailed design. The function, however, is set on a detailed level, and is far from an overall function. The length of a performance contract is five years, with an additional two-year option that usually is used and with bonuses and penalties used as a control mechanism. Several maintenance contracts are procured after each other during the life-cycle of the facility. Additionally, during the lifetime of the infrastructure reinvestments are needed to maintain its functionality.

The construction and maintenance of the infrastructure are the responsibility of two different divisions within the STA. The Investment Division participates in the Design and Construction phase, while the Traffic Division is involved in Maintenance contracts. Contractors formulate tenders based on detailed specifications provided by the STA, and procurement of the construction and subsequent maintenance are done independently. Traditional contracting, and specifically construction contracting, has several advantages such as being a familiar business model which all actors can relate to and calculate. The STA also emphasizes the fact that they know what they get, since the contract has been specified all the way to its end.

The current procurement practice is seen as resource-demanding from both buyer and providers. The procurement is viewed as inefficient; an example is the design results that are delivered by consultants that are not optimal for actual building. These quality issues are noticed by the contractor during the building phase, and result in lost time and money when the design has to be redone.

\section{IPSO contracts for rail infrastructure}

In this chapter, an outline of an IPSO contract for rail infrastructure is presented, followed by results from the individual interviews and the group interview, divided into benefits and challenges.

\subsection{Outline of an IPSO contract}

An IPSO contract for rail infrastructure can be described as a life-cycle contract including design, construction and maintenance, as seen in Figure 1 (Lingegård, 2012b). The outcome is measured in the performance and the availability of the facility, and the functional requirements are set on a higher level than for the design-build and performance contracts currently used for maintenance. The STA procures a function and does not specify in detail how the contractor should realize it, e.g. "build a railway from $\mathrm{A}$ to $\mathrm{B}$ with capacity $\mathrm{C}$ and maintain it for $\mathrm{X}$ years. After the contract period the railway should have required capacity Y." The initial planning of the stretch and the environmental evaluations would still be performed by the STA, since the phase includes e.g. redemption of house and environmental impact assessments that can make or break approval and realization of the project. The design of the construction and the maintenance is the responsibility of the contractor. The design and construction phases in the IPSO contract depend on the scale of the project, while the operations and maintenance phase is estimated by the actors to run between 10-45 years. 
RESPONSIBLE

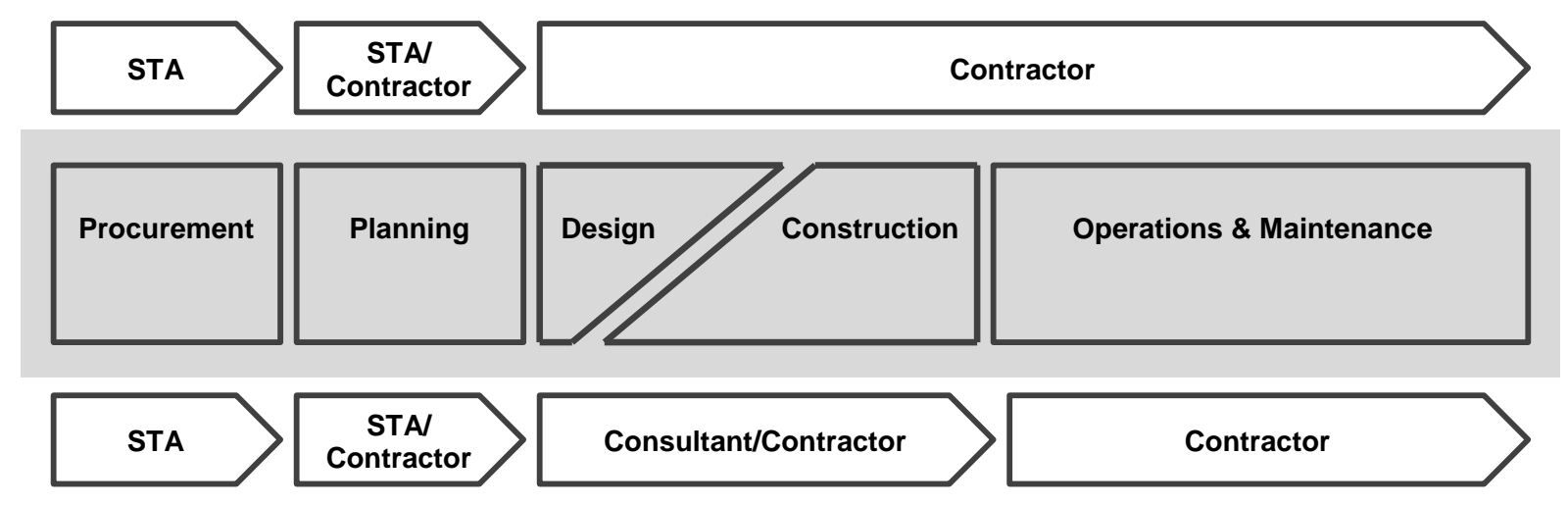

EXECUTOR

Figure 1: Schematic figure illustrating an IPSO contract for rail infrastructure (Lingegård, 2012a).

\subsection{Benefits of IPSOS}

\subsubsection{A life-cycle perspective}

According to contractors in this study, extended responsibility for them compared to today is required for development. An increased contractor responsibility would start a thinking process making use of the knowledge within the contractor organization. It was pointed out that the contractor would have to start thinking about where in the life-cycle they could make money and how. One of the contractors claimed that everything they build lasts for five years, but with longer contracts they would be more thorough. It would be more interesting for a contractor to use solutions that lower the operations and maintenance costs; this could be done with solutions that are more durable and do not require many measures. It was stated by most of the contractors that this would probably increase the lifetime of products.

In general, the STA believes that the contractor would build more durably if they knew they were to maintain the infrastructure for a longer period as well. Some of the STA respondents also believe that contractors would probably control the design consultants in a better way than the STA, which would save both time and energy compared with the current situation described in Chapter 4.

STA respondents think that the IPSO contract would provide more thought through construction in terms of maintenance. The holistic view would make contractors adopt a life-cycle perspective and consider the life-cycle costs of the infrastructure. The contracts would spur innovation development in the industry, since sufficiently skilled contractors would realize solutions providing a lower cost, which would result in a competitive advantage. This would be a driver for the whole industry to be innovative, but the development would start with small steps.

\subsubsection{Organizational synergies}

Contractors believe that from an organizational perspective, the benefits would be a smoother transition between the construction and the maintenance phases of the projects, as the knowledge is already within the organization. This knowledge could be used to discuss solutions in the organization and ensure that no one takes shortcuts, since the contractor is responsible for the entire project. A long-term contract would provide long-term planning, making it easier to make investments due to the longer payback time. Finally, it was said that this could lead to less focus on the lowest price, and 
instead the proposals with the best solutions could win the bidding. When talking about the best solutions the contractors meant from a life-cycle cost perspective.

\subsection{Challenges for IPSO contracts}

The challenges for IPSOs pointed out by the STA and the contractors are presented below. They are divided into three main categories: contractual, market-related and organizational.

\subsubsection{Contractual challenges}

The length of the contract - The length of an IPSO contract is important, but at the same time difficult to determine. According to the STA, it has to be long enough so that the contractor is forced to take the consequences in the maintenance phase for choices made during the design and construction phases. Also, it has to be long enough for the contractor to be able to make investments and build an organization around the project. Some STA respondents think that the contracts should last the entire economic lifetime of the infrastructure, but also add that this might not be possible due to increased uncertainties. If the contracts were as long as the lifetime of the material this would not be a problem, but different materials have different lifetimes, and it would be difficult to find the point in time where it would be most efficient to end the contract. According to contractors, the longer the contracts are, the more durable the construction must be. If the contracts are too long, however, it will be difficult to calculate and there will be a charge for the risk, increasing the societal costs, and that is not the point with this type of contract.

Evaluation and requirements - The STA believed that the procurement process would become longer, since it would take more time for contractors to calculate, and because the time for the STA to evaluate the offerings would increase. They mentioned the difficulty in evaluating a long-term contract, because it takes many years to get the overall picture. In addition, the complexity of defining functional requirements for the contracts, setting appropriate measures as well as measuring the residual value of the infrastructure will be challenging. The concerns about the functional requirements and the measuring were shared by the contractors.

Risk allocation - The way in which the risk would be shared with the IPSO contracts was one of the main concerns the contractors had, even though there were different opinions concerning how big of a challenge the increased risk-taking was. The IPSO contract would give contractors more risk, but some of them also identified more opportunity by becoming skilled in risk management. Negotiations during the course of the contract period were mentioned as a way to reduce the uncertainties. STA respondents agreed that the partner with the best ability to affect the risk should be the one with the responsibility for it. For the IPSO contracts, contractors would take all the responsibility and thereby more risk, which they might compensate for with a higher price on their offering. According to the STA, this increased risk-taking will have to be compensated for by intelligent solutions lowering costs for work processes and technical solutions.

\subsubsection{Market-related challenges}

The size of the contracts - The size of the contracts, geographically and in terms of volume and content, is a concern for contractors. The contracts have to be large enough to create the volume needed for investments but the contractors are also concerned that too many larger contracts would result in a locking of the market, leaving some contractors outside for years. This would then decrease the competition, which is already low. An IPSO is a large project and thus requires a large contractor, which according to the STA would exclude smaller organizations. 
The contractors and the STA believe that IPSO contracts would only work for new large investments due to two reasons. First, contracts have to be large enough to be economically beneficial to build an organization around it and to make investments. Second, documentation is lacking for the older infrastructure, resulting in too many uncertainties concerning the condition of the material and components.

Need for collaboration - Furthermore, one contractor could not realize this type of contract by itself; there is a need for both a general contractor making the foundation and a technical contractor building the actual rail infrastructure and performing the maintenance. The question is which one should be the IPSO contractor. The respondents feel that it would be logical if the technical contractor had the overall responsibility, since that is where the technical competence is located. On the other hand, these companies are in general too small, and a larger general contractor is better suited to lead such a project. Even though the number of national contractors that would leave tenders for an IPSO contract would be reduced, the respondents think that the number of international contractors would increase, since an IPSO contract is large enough for them to invest in Sweden.

\subsubsection{Organizational challenges}

Design competence - The IPSO contract is complex and the contractors believed that they would join forces, but the interface between them was identified as a difficulty. Currently, contractors do not have design competence within their organizations. The contractors would probably use the same consultants as the STA, but the majority of the respondents believed that the contractor would control the consultants better than the STA. To be able to do this, some contractors stated that they needed to have a competence base in-house, while others believed that a development division of their own would be necessary to achieve real, innovative solutions.

Continuity - The long-term survival of contractors was also mentioned, and the technical contractor did not believe that long-term resources would be a problem if they had the responsibility, but it would be a different story for the general contractors that would be dependent on the technical resources from outside their organizations. Another issue mentioned by the contractors related to the long-term perspective was that the interest within the contractors' organizations might disappear during the course of the contract, since the same people are not working in the organization during the entire period. This also relates to the continuity of IPSO projects that is needed on the market to maintain the competence within the organizations. One of contractors mentioned that the offering would probably not be immediately cheaper, since it takes time to learn.

Corporate culture - The Investment Division and the Traffic Division at the STA are two organizations that have little integration and very different ways of thinking. While the Investment Division has a project-oriented work form that follows an investment project, the work of the Traffic Division follows yearly cycles, i.e. fall-winter-spring-summer. Connecting these two divisions will not be done without friction, according to some respondents within the STA. Furthermore, STA respondents describe the organization as technically-oriented with a business culture where the employees, in general, are very interested in all the technical details of the contracts. This fits perfectly with the construction contracts but another approach, where contractors take the responsibility, needs to be adopted to work with IPSO contracts. The respondents describe this change as a hurdle the STA must pass to adopt an IPSO approach.

There are different opinions among the contractors concerning the competence and readiness of the STA. The IPSO contract is another business model and requires a new way of thinking; this part was seen as the most difficult for the STA. Most of the contractors do not believe that the STA is prepared 
for the higher price of the contracts compared to the initial purchasing price, and doubt the organization can evaluate the bids. Other contractors state that the STA has the competence but it needs to be communicated within the organization, meaning that more interaction is needed between the different divisions.

Competence - Competence is another area that was mentioned by STA respondents, and some stated that having people bound to long-term contracts would result in a lack of competent people in an industry that already has a shortage of competence in some areas. This means that they saw a risk for a shortage of work force in other projects if many people are tied up in long-term contracts. More competence in calculation and risk management is needed within the contractors' organizations. Concerning the competence regarding IPSO contracts within the STA, the STA respondents seemed to agree that most of it already exists, and that the major challenge is coordination, e.g. the cooperation between the Investment and Traffic Divisions. The importance of improving documentation, however, is emphasized. This is needed since the people procuring an IPSO will probably not be participating during the entire course of the contract.

Trust - An additional organizational concern among STA respondents is the relationship with contractors. Contractors believed that more transparency would be necessary as well as common goals for this type of contract to work. Another type of relationship is needed that is built on more trust than found in the current relationships. This is required since contractors will take over much of the responsibility that the STA has today, and the STA will have to take a step back. According to several of the respondents, however, this will be difficult due to the STA business culture. STA respondents still feel that some type of follow-up is needed for the IPSO contracts, since everything cannot be assigned to the legal framework and the regulations.

\section{Discussion}

The traditional construction contracts have advantages, such as being a familiar business model that is straightforward to calculate for contractors. This is in line with previous research, which states that an advantage with construction contracts is that the distinct roles of the buyer and contractors are clear (Pakkala, 2002). The STA knows exactly what will be built, but on the other hand the STA does not get more than asked for since the contractors are only are paid to follow the specifications. Detailed specifications do not optimize the innovation, since innovation typically comes through the contractor or supplier network (Pakkala, 2002).

\subsection{Technological lock-in and lack of knowledge transfer}

In the rail infrastructure industry, a dominant design for contracts has reached standardization and a focus on the lowest price. The focus in the standardization phase of a technology cycle should also be on efficiency (Schilling and Esmundo, 2009), which according to the respondents is not the case for the rail infrastructure industry.

Currently, the only actor that has the overall view and responsibility of a railway facility is the STA. This means that the STA should hold information concerning the condition of the rail infrastructure. However, today's information lacks detail and is not complete; contractors have no incitements to provide data from their operation. Also, gained knowledge is not transferred back to the STA and the design consultants when they design projects. There exists an information asymmetry, or even knowledge asymmetry, between the contractors, the STA and the consultants. Design and performance of a system can be improved by using knowledge about the system performance (Geyer and Davies, 
2000), but in this case this feedback loop is lacking. This results in wasted time and increased costs while the design is re-worked, which can be compared to the design paradox where product knowledge increases with time in the product life-cycle and modification costs increase, see e.g. Lindahl (2005). This is an example of the cost overruns that are usual for this type of contracting (Pakkala, 2002). Previous research states that construction firms do not fully use their experience due to lack of time or incentives to develop and capture it (Reichstein et al., 2008). This means that the next contract starts with the same information and knowledge level as the previous one, both for construction contracts and maintenance contracts.

The information and knowledge could potentially result in efficiency gains and technical development, since it is in the design phase the major decisions are taken (Lewis and Gertsakis, 2001). The technology and design is locked for the whole life-cycle of the facility, when it has been realized, but there is on the other hand room for incremental innovation (Christensen, 2000). This will however only be possible if the information concerning failures and possible improvements is transferred back to the STA and incorporated into the design. The same standards are chosen repeatedly, since there are no feedback loops bringing back information and knowledge that challenges the current technology and standards. This is an example of how the existing structures, such as behavior patterns and work practice, are enabling and reinforcing the existing technology (Perkins, 2003).

\subsection{Developing a more durable railway}

An IPSO with a fixed price could provide incentives for minimum input and maximum utilization of the elements in the offering, see e.g. (Meier et al., 2010). This is in line with theories of how dematerialization can reduce environmental impact (Mont, 2000). The life-cycle perspective was mentioned by the actors as a possible way of achieving a more durable railway when balancing the construction and maintenance costs. This is in accordance with previous research on infrastructure projects (Pakkala, 2002; White et al., 1999). Suppliers involved in operational activities, e.g. maintenance, can establish feedback loops between the design phase and the railway operations (Geyer and Davies, 2000). Contractors believe that they can be more creative, and thereby affect the rest of the life-cycle if they are involved in the design phase.

Similar to quality issues, decreasing the environmental impacts from the environmental considerations of the facilities needs to be incorporated into the design phase to be efficient (Sakao, 2007). The actors' focus is on cost reduction and process efficiency, but this indirectly results in a focus on reduction of environmental impact as well. Contractors will, using the IPSO business model, make sure that the facility is as durable as possible to reduce maintenance and changing of spare parts, which implies less use of resources such as material and energy. This is in line with previous research stating that IPSOs provide incentives for providers to optimize the use of resources (Lindahl et al., 2009; Tukker and Tischner, 2006).

\subsection{Internal resistance and new competence}

Only changing the business model and contracts would be insufficient, since the relational issues are required and determined by the business needs (Thompson et al., 1998). A major hurdle in this case seems to be the organization and culture at the STA, which lack a long-term overall perspective in combination with an internal reluctance to change and develop the process of contracting. The challenge is related to the change of mindset within the organization and the need for internal marketing (Sundin et al., 2009). 
Providers need to develop new skills for understanding long-term risk as well as be able to identify, evaluate and manage risk (Brady et al., 2005). In this case, this goes for both contractors and the STA due to the complex structure and the relations between the actors. A multi-skilled and cross-functional team is needed to produce the offering (Brady et al., 2005). Contractors can already identify potential synergies within their own organizations as a result the holistic work practice and the cross-functional approach. The construction and maintenance phases would benefit from the fact that all knowledge would be in the same organization and solutions could be discussed from a life-cycle perspective. Previous research has shown that projects with an integrated process, such as IPSO projects for infrastructure, result in projects being completed faster (Pakkala, 2002). Other changes needed are more cooperation between the Investment and Traffic Divisions at the STA, and the need for both a general contractor and a technical contractor to fulfill the cross-functional skills required.

\subsection{Trust and improved information sharing}

Risk of unpredictable costs can be reduced by access to resources, and the trust in a relationship can be helped by sharing information ( $\mathrm{Ng}$ and Nudurupati, 2009). This shows how important transparency and information and knowledge sharing will be for the IPSO contracts to work. IPSO contracts would provide incentives for documentation, since the contractor has to demonstrate the value of the facility at the end of the contract, as well as to have measures for evaluation during the contracts. For a contractor, upgrading or redesigning is not easy due to the technological lock-in. On the other hand, the processes for maintenance can be developed during the contract using the knowledge and experience gained during the use phase of the IPSO contracts, see e.g. Meier et al. (2010).

It has also been stated that a formal relationship is not enough for an IPSO contract, and for the partnership to be successful there is a need to align the profit incentives between them (Lockett et al., 2011). The STA and contractors see themselves as parties with opposing interests. This could also mean that they have competing goals, which is opposite to what is recommended for mutual gains (Emden et al., 2006). There seems to be a lack of trust between the parties, which can lead to additional relational costs, see e.g. Bunduchi and Smart (2010). Long-term cooperation calls for common interests, shared risks and flexibility rather than making one side take all the risk (NysténHaarala et al., 2010). If contractors are going to use their knowledge to improve the infrastructure, it is likely that some of their competitive advantage depends on keeping this knowledge within the firm. Therefore, the contract has to regulate how to deal with this, so that the knowledge can transfer to other projects without jeopardizing the innovation firm. There could, for example, be a delay for the use of the knowledge for anyone but the innovation firm.

\section{Conclusions and future research}

IPSO contracts would add a life-cycle perspective to the rail infrastructure and much needed contractor involvement. By involving the contractors in the design phase their knowledge could be used in a better way, creating a feedback loop from practice to design. IPSOs provide incentives for more durable construction, requiring less maintenance and spare parts, and thereby creating a more resource-efficient rail infrastructure. Even though the IPSOs have many advantages acknowledged by both the STA and the contractors, they are skeptical to its actual implementation, and change will take time. New investments for rail infrastructure are rare, implying that the development of contracts is slow, and the decisions taken will have far-reaching consequence since the life-cycle of the infrastructure is long. 
The main challenges today are the lack of information and the transfer of knowledge from the contracts to the actors. This would have to be dealt with, which requires a change in the providerbuyer relationship including more trust. Also, the buyer's conservative business culture makes it difficult to implement new types of contracts. IPSO contracts require a change in mindset from the actors and improved information and knowledge sharing, something which stimulates innovation as well as processes for evaluation of the contracts.

This paper has discussed considerations and feasibility of a potential implementation of IPSO contracts, using the case of the rail infrastructure in Sweden. However, the conclusions can be valid in other geographical locations as well, e.g. where a public authority acts as a buyer on a market regulated by public procurement. The results can also be valuable for other large technical systems, such as road and district heating, and for markets with one dominant actor and only a few providers.

\subsection{Future research}

The natural next step in this research would be to show the improvement potential for rail infrastructure using IPSOs in a quantitative way, making use of life-cycle assessment and life-cycle cost analysis for environmental and economic calculations. Additionally, the risk factors will be investigated more thoroughly, as well as the functional requirements needed for an IPSO contract.

\section{Acknowledgement}

The authors would like to thank the Swedish Transport Administration for financing the research and the respondents for contributing with their time and knowledge.

\section{References}

Ahmed, P.K., Shepard, C.D., 2010. Innovation management: context, strategies, systems and processes. Pearson Education Limited, Essex.

Alexandersson, G., Hultén, S., 2008. The Swedish Railway Deregulation Path. Review of Network Economics 7.

Alonso-Rasgado, T., Thompson, G., Bergström, B.-O., 2004. The design of functional (total care) products. Journal of Engineering Design 15, 515-540.

Baines, T.S., Lightfoot, H.W., Evans, S., Neely, A., Greenough, R., Peppard, J., Roy, R., Shehab, E., et al., 2007. State-of-the-art in product service-systems. Journal of Engineering Manufacture 221, 1543-1552.

Berggren, C., Björkman, M., 2002. Funktionsförsäljning/funktionsupphandling för hållbar tillväxt - Idépromemoria och kunskapsöversikt [Functional sales/procurement for sustainable growth]. Department of Management and Engineering, Linköping University.

Brady, A., Davies, A., Gann, D.M., 2005. Creating value by delivering integrated solutions. International Journal of Project Management 23, 360-365.

Bunduchi, R., Smart, A.U., 2010. Process Innovation Costs in Supply Networks: A Synthesis. International Journal of Management Reviews 12, 365-383.

Christensen, C.M., 1992. Exploring the Limits of the Technology S-Curve. Part 1: Component Technologies. Production and Operations Management 1, 334-357.

Christensen, C.M., 2000. The innovator's dilemma. Harper Business: An imprint of HarperCollins Publishers, New York. 
Chung, S., Kim, G.M., 2003. Performance effects of partnership between manufacturers and suppliers for new product development: the supplier's standpoint. Research Policy 32, 587603.

Emden, Z., Calantone, R.J., Droge, C., 2006. Collaborating for new product development: Selecting the partner with maximum potential to create value. Journal of Product Innovation Management 23, 330-341.

Erkoyuncu, J., Roy, R., Shehab, E., Cheruvu, K., 2011. Understanding service uncertainties in industrial product-service system cost estimation. The International Journal of Advanced Manufacturing Technology 52, 1223-1238.

Geyer, A., Davies, A., 2000. Managing project-system interfaces: case studies of railway projects in restructured UK and German markets. Research Policy 29, 991-1013.

Government Offices of Sweden, 2010. Förbättrad vinterberedskap inom järnvägen [Improved winter preparations for railway], in: The Ministry of Enterprise Energy and Communications (Ed.).

Handfield, R.B., Ragatz, G.L., Petersen, K.J., Monczka, R.M., 1999. Involving Suppliers in New Product Development. California Management Review 42, 59-82.

Hedström, R., Ihs, A., Sjögren, L., 2005. Funktionsupphandling av väg- och banhållning, Problem och möjligheter. [Functional procurement of road and rail maintenance. Problems and opportunities]. Swedish National Road and Transport Research Institute, Linköping.

Lenferink, S., Tillema, T., Arts, J., 2013. Towards sustainable infrastructure development through integrated contracts: Experiences with inclusiveness in Dutch infrastructure projects. International Journal of Project Management 31, 615-627.

Lewis, H., Gertsakis, J., 2001. Design+environment: a guide to designing greener goods. Greenleaf publishing, Sheffield.

Lindahl, M., 2005. Engineering Designers' Requirements on Design for Environment Methods and Tools, Doctorial dissertation, Department of Machine Design. Royal Institute of Technology, Tockholm.

Lindahl, M., Sakao, T., 2013. Environmental and Economic Contribution of Design Changes in Integrated Product Service Offerings, in: Meier, H. (Ed.), Product-Service Integration for Sustainable Solutions. Springer, Bochum, Germany.

Lindahl, M., Sundin, E., Sakao, T., 2013. Environmental and economic benefits of Integrated Product Service Offerings quantified with real business cases. Journal of Cleaner Production 64, 288-296.

Lindahl, M., Öhrwall Rönnbäck, A., Sakao, T., 2009. Business Implications of Integrated Product Service Offerings and Resulting Potential Engineering Issues, Proceedings of the 17th International Conference on Engineering Design ICED09, Stanford, USA.

Lingegård, S., 2010. PSS for rail and road infrastructure: a literature study. Department of Management and Engineering, Linköping University.

Lingegård, S., 2011. PSS Contracts for Rail Infrastructure, The R\&D Management Conference 28-30 June Norrköping Sweden.

Lingegård, S., 2012a. Integrated Product Service Offerings for Rail Infrastructure: potential benefits and challenges, Licentiate, Environmental Technology and Management, Department of Management and Engineering. Linköping University, Linköping. 
Lingegård, S., 2012b. Integrated Product Service Offerings for Rail Infrastructure: potential benefits and challenges, Licentiate Thesis, Environmental Technology and Management, Department of Management and Engineering. Linköping University, Linköping.

Lingegård, S., Lindahl, M., Sundin, E., 2010. Organizational changes in connection with IPSO, in: Tomohiko Sakao, T.L., Mattias Lindahl (Ed.), CIRP's 2nd IPS² Conference, Linköping, 14-15 April, Linköping, pp. 461-466.

Lingegård, S., Sakao, T., Lindahl, M., 2011. Integrated Product Service Engineering - Factors Influencing Environmental Performance, in: Cogan, B. (Ed.), Systems Engineering - Practice and Theory. InTech.

Lockett, H., Johnson, M., Evans, S., Bastl, M., 2011. Product Service Systems and supply network relationships: an exploratory case study. Journal of Manufacturing Technology Management 22, 293-313.

Malerba, F., 2002. Sectoral systems of innovation and production. Research Policy 31, 247264.

Meier, H., Roy, R., Seliger, G., 2010. Industrial Product-Service Systems - IPS². CIRP Annuals - Manufacturing Technology 59, 607-627.

Mont, O., 2000. Product Service Systems Naturvårdsverket - The Swedish Environmental Protection Agency, Stockholm.

Mont, O., 2004. Product-Service Systems: Panacea or Myth?, Doctorial dissertation, The International Institute of Industrial Environmental Economics. Lund University, Lund.

Mont, O.K., 2002. Clarifying the concept of product-service system. Journal of Cleaner Production 10, 237-245.

$\mathrm{Ng}$, I.C.L., Nudurupati, S.S., 2009. Outcome-based service contracts in the defence industrymitigating the challenges. Journal of Service Management 21, 656-674.

Nilsson, J.-E., 2009. Nya vägar för infrastruktur [New ways for infrastructue]. SNS Förlag, Stockholm.

Nilsson, J.-E., Bergman, M., Pyddoke, R., 2005. Den svåra beställlarrollen [The difficult role of the procurer]. SNS Förlag, Stockholm.

Nilsson, J.-E., Ihs, A., Leif, S., Wiman, L.G., Wågberg, L.-G., 2006. Funktionsupphandling. Sammanfattning av kunskapsläget och rekommendationer för fortsatt forskning [Functional procurement. Summary of the field of knowledge and recommendations for future research]. Swedish National Road and Transport Research Institute, Linköping.

Nilsson, J.-E., Pyddoke, R., 2007. Offentlig och privat samverkan kring infrastruktur - en forskningsöversikt [Public Private Partnership for infrastructure - a research overview]. Swedish National Road and Transport Research Institute, Linköping.

Nystén-Haarala, S., Lee, N., Letho, J., 2010. Flexibility in contract terms and contracting processes. International Journal of Managing Projects in Business 3, 462-478.

Oliva, R., Kallenberg, R., 2003. Managing the transition from products to services. International Journal of Service Industry Management 14, 160-172.

Pakkala, P., 2002. Innovative Project Delivery Methods for Infrastrucutre. Finnish Road Enterprise, Helsinki.

Perkins, R., 2003. Technological lock-in, Internet Encyclopedia of Ecological Economics. International Society of Ecological Economics, International Society of Ecological Economics, http://www.isecoeco.org/. 
Reichstein, T., Salter, A.J., Gann, D.M., 2008. Break on Through: Sources and Determinants of Product and Process Innovation among UK Construction Firms. Industry and Innovation 15, 601-625.

Sakao, T., 2007. A QFD-centred design methodology for environmentally conscious product design International Journal of Production Research 45, 4143-4162.

Schilling, M.A., Esmundo, M., 2009. Technology S-curves in renewable energy alternatives: Analysis and implications for industry and government. Energy Policy 37, 1767-1781.

Sundin, E., Bras, B., 2005. Making Functional Sales Environmentally and Economically Beneficial through Product Remanufacturing. Journal of Cleaner Production, 13, 913-925.

Sundin, E., M. Lindahl, A. Öhrwall Rönnbäck, G. Ölundh Sandström,J. Östlin, , 2006. Integrated Product and Service Engineering Methodology, 11th International Conference of Sustainable Innovation, Chicago, USA.

Sundin, E., Ölundh Sandström, G., Lindahl, M., Öhrwall Rönnbäck, A., 2009. Industrial Challenges for Product/Service SYstems: Experiences from a large company netowork in Sweden, CIRP Industrial Product-Service Systems (IPS²) Conference, Cranfield UK.

Svensson, N., 2006. Life-Cycle Considerations for Environmental Management of the Swedish Railway Infrastructure, Doctorial thesis, Department of Mechanical Engineering. Linköping University, Linköping.

Svensson, N., Eklund, M., 2007. Screening of environmental pressure from products in the Swedish railway infrastructure: Implications for strategic environmental management. Resources, Conservation and Recycling 52, 248-265.

The Swedish Agency for Public Management [Statskontoret], 2009. Sega gubbar? En uppföljning av Byggkommisionens betänkande "Skärpning gubbar!" [Follow-up on report from the Construction commission]. The Swedish Agency for Public Management,.

The Swedish National Audit Office [Riksrevisionen], 2010. Underhåll av järnväg [Railway maintenance], Stockholm, Sweden.

The Swedish Transport Administration, 2012. The Swedish Transport Administration, Annual Report 2012, Borlänge, Sweden.

The Swedish Transport Administration, 2013. Förslag till nationell plan för transportsystemet 2014-2025 [Suggestions for a national plan for the transport system 2014-2025]. The Swedish Transport Administration, Borlänge, Sweden.

Thompson, I., Cox, A., Anderson, L., 1998. Contracting strategies for the project environment. European Journal of Purchasing \& Supply Management 4, 31-41.

Trott, P., 2012. Innovation management and new product development, Fifth edition ed. Pearson Education Limited, Essex.

Tukker, A., 2004. Eight types of product-service system: eight ways to sustainability? Experiences from suspronet. Business Strategy and the Environment 13, 246-260.

Tukker, A., Tischner, U., 2006. Product-services as a research field: past, present and future. Reflections from a decade of research. Journal of Cleaner Production 14, 1552-1556.

Tullberg, M., 2000. Växelsång: Om organisation för förändring på SJ [Organizatinal change for Swedish Rail], Doctorial Thesis, Företagsekonomiska institutionen. University of Gothenburg, Göteborg, Sweden.

van Amstel, M., Driessen, P., Glasbergen, P., 2008. Eco-labeling and information asymmetry: a comparison of five eco-labels in the Netherlands. Journal of Cleaner Production 16, 263-276. 
Sofia Lingegård, Mattias Lindahl, Integrated Product Service Offerings for rail infrastructure - benefits and challenges regarding knowledge transfer and cultural change in a Swedish case, Journal of Cleaner Production, Volume 98, 1 July 2015, Pages 166-174

White, A.L., Stoughton, M., Feng, L., 1999. Servicizing: The Quiet Transistion to Extended Product Responsability. Tellus Institute, Boston. 